\title{
An Analysis on Urban Labor Market Integration of the Beijing-Tianjin-Hebei Region from the Perspective of Labor Wage
}

\author{
Ruqing $\mathrm{Xu}$ \\ School of Economics and Management \\ Beijing Jiaotong University \\ Beijing, China
}

\begin{abstract}
The coordinated development of the BeijingTianjin-Hebei region focuses on the integration, especially on the unified labor market. From the perspective of labor wages, the article uses the average real wages of urban staffs and workers among the 13 cities in Beijing-Tianjin-Hebei region from 2004 to 2013 to measure the labor market integration level, by analyzing the average real wages, the mean absolute deviation of average wages, the coefficient of variation of average wages and the panel data. The study shows that the mean absolute deviation of average real wage tends to increase with a slow pace. It also says that the labor wages first diverge then converge and finally tend to be the same, which means that the integration of labor market is developing but are still in the state of fragmentation; The panel data illustrates that the labor wages in the Beijing-Tianjin-Hebei region tend to converge slowly. Therefore, the wages among this region tend to be integrated, meanwhile, the whole labor market is approaching to the integration regardless of the present fragmentation.
\end{abstract}

Keywords-regional labor economics; integration of labor market; labor wage; the Beijing-Tianjin-Hebei region

\section{INTRODUCTION}

The inter-regional labor market integration has always been a direct manifestation of the development of the market economy to a certain height. It represents whether the labor resources in a region can be rationally optimized and configured. It is an important signal to reflect whether the market of an economy is functioning well and whether it is highly competitive. As one of the three major urban agglomerations in China, the Beijing-Tianjin-Hebei region has important significance for promoting the development of the Bohai Rim Economic Zone and driving the hinterland of the North. Since 2014, the coordinated development of the BeijingTianjin-Hebei region has become an important national strategy. It has entered a stage of comprehensive deepening. The vitality of labor mobility among cities is significantly higher than that of urban-rural labor mobility under the traditional dual economic structure. It should be the core part of the current labor market integration. In this context, the measurement and analysis of the integration of the BeijingTianjin-Hebei region has important research value and significance, especially the study of the indispensable production factors of urban labor. Therefore, this paper intends to analyze the degree of integration of the Beijing-Tianjin-
Hebei labor market, which is mainly represented by urban labor, from the perspective of wages.

\section{LITERATURE REVIEW}

Throughout the domestic and international research, the measurement of labor integration has more research and measurement in other markets, but less research on the interregional labor market. The classical school assumes that the labor market is a completely competitive market, and wages as a price signal adjusts the supply-demand relationship between the free movement of labor in the region. In the end, the labor wages between regions will tend to be integrated. Foreign scholars have conducted some theoretical and empirical research on this.

Topel (1986) proposed a classic labor market dynamic equilibrium model. It is believed that under the premise of free labor movement, homogeneous labor in different regions of the region will flow due to wage differences, and the final wage difference will be reduced due to the free flow of labor. It is reflected in the integration of labor market in the region; it is also considered that the wage elasticity of different labor groups is different, and the wages lacking liquidity have higher flexibility [1]. Barro and Sala-i-Martin (1992) more intuitively study the integration of labor market from the perspective of per capita income convergence between different regions of the same region, through the convergence of per capita income between the United States and the different economies in Western Europe. The study found that labor market integration exists in the region and the integration speed is slow, and the contribution rate of labor free mobility to labor market integration can reach about 1/3 [2]. In the same year, Blanchard and Katz measured the labor market integration in the region in terms of unemployment rate and employment growth rate in the US states. Labor flow is the main mechanism for the labor market to become integrated. The main reason for labor mobility is Changes in unemployment rate rather than changes in wages [3]. On this basis, Borjas (2001) extracted the most liquid Mexican immigrants in the US labor market for research. The results confirmed that the migration of Mexican immigrants has a more significant role in promoting the speed of US labor market integration [4]. 
Chinese scholars have also done a lot of research in these areas. Du Yang and Cai Wei (2004) analyzed the convergence of wages between regions by examining the time-series data of provinces in China's manufacturing industry in 1995-2002. The results of the study show that the degree of segmentation in China's labor market is gradually decreasing [ 5]. Yang Tao and Sheng Liugang (2007) believe that the wages of workers with lower education level converge faster than those with high education level, and the gap between wages and education returns in cities will increase with the increase [6]. Zhou Shen and Yi Miao (2010) analyzed the labor market and the mechanisms and ways that affect its integration, and concluded that the equilibrium wages in two different labor market gaps can better measure the degree of labor market integration in China [7]. Zhao Sanwu and Qian Xueya (2014) used the price index method to measure the trend of China's overall labor market integration. The results show that this trend is increasing year by year [8].

It is not difficult to find out through the combing of the existing literature research that there are two shortcomings: First, there are few studies on the labor market integration in the Beijing-Tianjin-Hebei region, and it is only involved in the overall integration study of Beijing-Tianjin-Hebei. At the same time, the analysis of labor market integration is mostly concentrated in the Yangtze River Delta and Pearl River Delta regions, and there are few studies on quantitative analysis. Second, the literature has focused on the measurement of labor mobility between traditional urban and rural areas, and there is less research on the labor market between cities. In view of this, based on the perspective of wage integration, this paper will base on the multiple dimensions of wages, and calculate the absolute average dispersion of real wages and the average real wage dispersion coefficient of 13 cities in the Beijing-TianjinHebei region over the years (2003-2014). And the inspection of panel data to measure the degree and trend of urban labor market integration in Beijing-Tianjin-Hebei region, and put forward corresponding policies and recommendations.

\section{MEASUREMENT OF WAGE INTEGRATION IN THE LABOR MARKET IN THE BEIJING-TIANJIN-HEBEI REGION}

During the period of 2004-2013, the coordinated development of the Beijing-Tianjin-Hebei region quickly entered a new stage. In February 2004, the Beijing-TianjinHebei regional economic development strategy seminar was held in Langfang, Hebei Province. The three places reached the "Langfang Consensus", officially determined the development of "Beijing-Tianjin-Hebei economic integration", and the significance of economic cooperation in the Bohai Rim region. In November of the same year, the National Development and Reform Commission initiated the preparation of the "BeijingTianjin-Hebei Metropolitan Area Plan" and adopted the "2+8" model, namely, Beijing-Tianjin plus Hebei Shijiazhuang, Baoding, Tangshan, Qinhuangdao, Langfang, Zhangzhou, Zhangjiakou and Chengde. 8 cities. In 2011, the concept of "Capital Economic Circle" was written into the national "Twelfth Five-Year Plan" strategy and became one of the major national strategies. In July 2013, the Beijing party and government delegation went to Tianjin to sign the first comprehensive strategy between Beijing and Tianjin. Cooperation Agreement "Beijing-Tianjin Cooperation Agreement"; In February 2014, President Xi Jinping hosted a symposium in Beijing, proposing seven requirements for promoting the coordinated development of the Beijing-TianjinHebei region, emphasizing the need to consciously break the thinking of "one acre and three points" Formulate and promote the innovation of regional development system and mechanism. Therefore, this period is a crucial period for the coordinated development of the Beijing-Tianjin-Hebei region. The research on the data from this interval will be more representative. The main data of this paper are from the China Urban Statistical Yearbook of 2004-2015, the statistical yearbook of Beijing, Tianjin and Hebei, the statistical yearbook of each city to be studied and the annual statistical bulletin of national economic and social development.

\section{A. Analysis of the average absolute deviation of wage levels in the Beijing-Tianjin-Hebei region}

Table 1 shows the average real wages of employees in the 13 cities in the Beijing-Tianjin-Hebei region from 2004 to 2013 (the effect of the price level has been removed). The average real wages of Beijing and Tianjin over the years can be clearly seen from the table. The average water level is higher than that of 11 cities in Hebei Province. The wage level in Beijing has been at the highest level in the labor market in the Beijing-Tianjin-Hebei region and continues to rise. The wage levels in Tangshan City, Qinhuangdao City and Langfang City increased significantly in the past decade. In particular, Tangshan City's wage level surpassed Qinhuangdao City after 2006. At the same time, the wage level in Langfang City climbed rapidly, and it was in Hebei in ten years. The province's wage level is at the forefront; the wage levels in Zhangjiakou City and Hengshui City have been low, and the average real wage level in Hengshui City is the lowest level in the Beijing-Tianjin-Hebei region over the years.

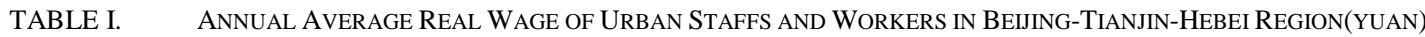

\begin{tabular}{|c|c|c|c|c|c|c|c|c|c|c|c|c|c|c|}
\hline Years & Beijing & Tianjin & Shijiazhuang & Tangshan & Qinhuangdao & Handan & Xingtai & Baoding & Zhangjiakou & \begin{tabular}{|l|} 
Zhengde \\
\end{tabular} & Cangzhou & Langfang & Hengshui & Baoding \\
\hline 2004 & 29380 & 21400 & 13130 & 13580 & 15840 & 11930 & 11720 & 11880 & 11760 & 12370 & 11200 & 12810 & 10280 & 11880 \\
\hline 2005 & 39520 & 24900 & 15000 & 16730 & 17340 & 13500 & 13300 & 13120 & 13300 & 13650 & 14330 & 14740 & 11840 & 13120 \\
\hline 2006 & 39760 & 28260 & 16610 & 19300 & 19420 & 15020 & 14900 & 14630 & 15100 & 14710 & 16500 & 17430 & 13230 & 14630 \\
\hline 2007 & 45420 & 33530 & 19110 & 22290 & 21440 & 17400 & 17260 & 17000 & 17980 & 17640 & 19670 & 21020 & 15140 & 17000 \\
\hline 2008 & 53590 & 39270 & 21320 & 28000 & 27440 & 22230 & 21300 & 20700 & 22260 & 22600 & 24020 & 27200 & 18350 & 20700 \\
\hline 2009 & 59030 & 45530 & 27290 & 33400 & 32790 & 27450 & 26040 & 24920 & 26680 & 27020 & 38120 & 32580 & 23000 & 24920 \\
\hline 2010 & 64140 & 51170 & 30540 & 36080 & 34920 & 31000 & 27390 & 27220 & 29610 & 29320 & 32080 & 36250 & 25240 & 27220 \\
\hline 2011 & 71810 & 53040 & 33240 & 39880 & 35190 & 34200 & 33100 & 29560 & 31780 & 32330 & 34380 & 36950 & 26930 & 29560 \\
\hline 2012 & 82580 & 63680 & 37380 & 44260 & 44270 & 36990 & 36860 & 33960 & 34820 & 33960 & 39030 & 43980 & 32170 & 33960 \\
\hline 2013 & 90990 & 66800 & 42420 & 47280 & 47130 & 39040 & 38400 & 38640 & 35510 & 41500 & 42330 & 47900 & 35650 & 38640 \\
\hline
\end{tabular}


In order to further explore the degree of labor market uniformity in the Beijing-Tianjin-Hebei region, we calculate the deviation between the actual wage level of each city and the average wage level in the current period and the average absolute deviation of the actual wage level by the following formula:

Among them, the number of cities in the study area is $n, i$ is the city inspected, $t$ is the year, and $\mathrm{Wi}$ is the average salary of each city over the years, which is the average salary of the Beijing-Tianjin-Hebei region in each year.

$$
\begin{gathered}
\mathrm{D}_{\mathrm{t}}=\mathrm{W}_{\mathrm{i}}-\overline{\mathrm{W}_{\mathrm{t}}} \\
\overline{\mathrm{D}_{\mathrm{t}}}=\frac{\sum_{\mathrm{i}=1}^{\mathrm{n}}\left|\mathrm{W}_{\mathrm{i}}-\overline{\mathrm{W}_{\mathrm{t}}}\right|}{\mathrm{n}}
\end{gathered}
$$

By comparing the difference between the wages of cities in 2004-2013 and the average wage level in the region in Table 1, it can be seen that the wage level differentiation in the labor market in Beijing-Tianjin-Hebei region is more obvious, and the average wage level deviation in Beijing and Tianjin has always been worse. Large, the average salary of the two years is significantly higher than the average wage in the region, and significantly higher than in other cities in Hebei Province. The average annual wages of Tangshan and Qinhuangdao are basically higher than the average level in the whole region. The deviation of most years is positive. The average wages of Langfang and Zhangzhou in 2004-2008 are increasing and accompanied by fluctuations, except for the above four cities. The wages of other cities in the province are lower and are at a lower level.

Through the calculation of the above formula, the line graph of the average absolute deviation of the average wage level of each city in Beijing-Tianjin-Hebei region from 2004 to 2013 as shown in Fig. 1 is further obtained. It can be clearly seen from the figure that 13 cities in the Beijing-Tianjin-Hebei region The average absolute wage gap has increased year by year with the increase of time. Among them, the wage difference between Beijing, Tianjin and Hebei has increased significantly from 2011 to 2012, but the average annual growth rate of the spread has slowed down as a whole. trend. Therefore, from the perspective of the average absolute deviation of wages, the labor market in the Beijing-TianjinHebei region still has a phenomenon of differentiation, and the degree of differentiation has increased slightly.

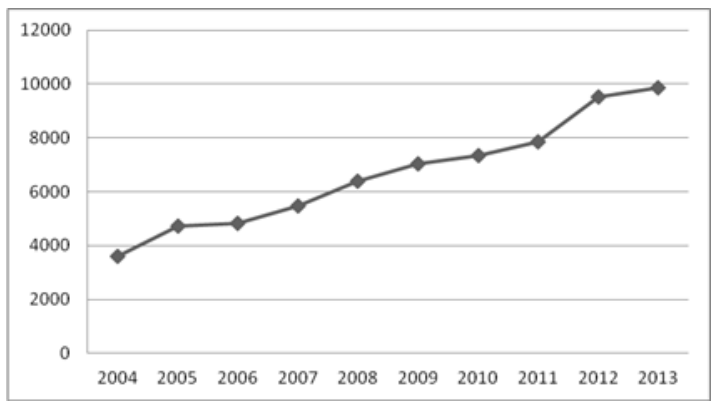

Fig. 1. The Mean Absolute Deviation of Each City's Average Wage in Beijing-Tianjin-Hebei Region from 2004 to 2013
B. Comparison of the Discrete Coefficients of Average Wage of Staff and Workers in the Beijing-Tianjin-Hebei Region

In order to further investigate the trend of real wage changes in the Beijing-Tianjin-Hebei region, the standard deviation and the dispersion coefficient (standard deviation coefficient) will be used for comparative analysis. The standard deviation over the years reflects the degree of dispersion between the wage level and the average wage level in each city. The larger the standard deviation, the more diverging the wage level between cities. Conversely, the smaller the standard deviation or the more constant, the higher the inter-city wage level. And there is a trend towards integration across the labor market. The discrete coefficient is a more intuitive and accurate measure of the dispersion of wage levels in the BeijingTianjin-Hebei region in different years.

Fig. 2 is a time chart of the standard deviation of the average wage level in the Beijing-Tianjin-Hebei region from 2004 to 2013. As can be seen from the figure, since 2004, the standard deviation of the average wage level in Beijing, Tianjin and Hebei has generally been on the rise. The growth rate of the standard deviation between 2004-2005 and 2001-2012 is relatively high. There was a slight decrease in the standard deviation between 2005 and 2006.

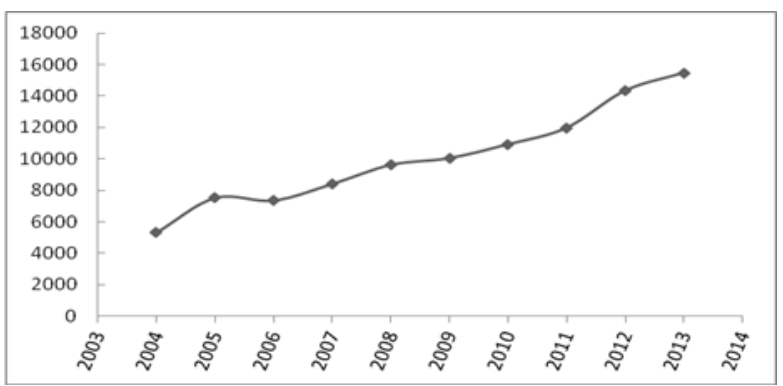

Fig. 2. The Standard Deviation of The Average Wage in Beijing-TianjinHebei Region from 2004 to 2013

Due to the different average wages over the years, only the standard deviation of each year can not accurately reflect the degree of dispersion of the wage level. The calculation and analysis of the discrete coefficients are performed on the basis of the standard deviation. It can be seen from Fig. 3 that the dispersion coefficient of the wage level in the Beijing-TianjinHebei region has a rising process from 2004 to 2005, reaching the highest point in the decade in 2005, and has been declining and gradual until 2013. . Therefore, on the whole, the average wage level in the Beijing-Tianjin-Hebei region is a process of convergence and convergence after the first divergence, which indicates that the average wage level in the Beijing-TianjinHebei region tended to converge between 2004 and 2013, and the labor market is also integrated. In the process of becoming. Due to data acquisition and estimation problems, the phenomenon of rising dispersion coefficient from 2004 to 2005 needs further observation and research. 


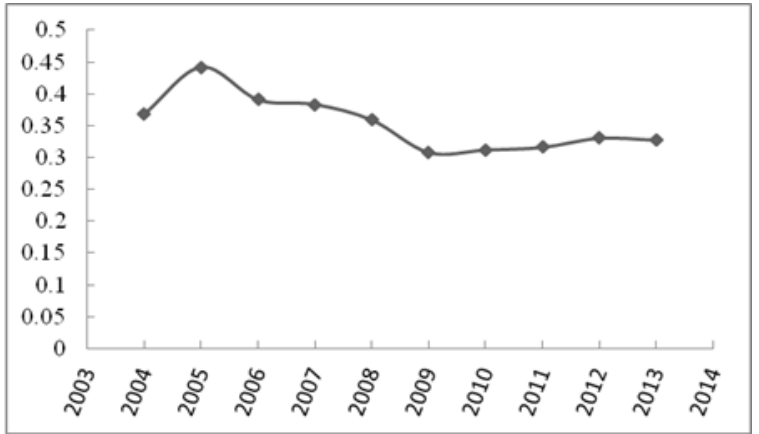

Fig. 3. The Coefficient of Variation of The Average Wage in BeijingTianjin-Hebei Region from 2004 to 2013

\section{Regression of Panel Data for Salary Integration in Beijing-Tianjin-Hebei Region-Test of Convergence Coefficient}

In order to test whether there is convergence of real wages in 13 cities in the Beijing-Tianjin-Hebei region, we will improve on this basis by drawing on the calculation methods of Yang Tao and Sheng Liugang (2007), and establish the following wage level convergence test model, using 13 Beijing-Tianjin-Hebei regions. The data of the actual average wage level of the city in 2004-2013 is returned to the panel data:

\section{$\left(\log W_{i, 2013}-\log _{i, 2004}\right) / t=\alpha+\beta \log _{i, 2004+\varepsilon i}$}

Among them, Wi, $\mathrm{t}$ is the actual average wage of $\mathrm{i}$ city in $\mathrm{t}$ year, $\beta$ is the convergence coefficient, $\log W i, 2004, \log W i$, 2013 respectively represent the actual average wage logarithm transformation of cities in 2004 and 2013. If $\beta$ on the right side of the equation is negative and passed the test of the equation, it indicates that the initial wage level of a certain city is inversely proportional to the average wage growth rate of the city, that is, the wage level between cities tends to converge. The regression results are as follows:

$\left(\log W_{i, 2013}-\log W_{i, 2004}\right) / t=0.258027-0.01314 \log W_{i, 2004+} \varepsilon i$

\section{(3.602993)(-1.749263)}

The F value was 3.059922 and the DW value was 1.366431 The coefficients of $\alpha$ and $\beta$ were all tested by the $10 \%$ significance test, and the equation also passed the $10 \%$ significance test, but the overall fit of the equation was low. The regression results show that the convergence coefficient of wages in the 13 cities of Beijing-Tianjin-Hebei region was negative in 2004-2013, which is in line with the above convergence expectations, but the overall convergence trend is not obvious, and the convergence rate is slow.

\section{CONCLUSIONS AND RECOMMENDATIONS}

\section{A. Research conclusions}

From the perspective of wages, this paper analyzes the average wage level of employees in 13 cities in BeijingTianjin-Hebei region from 2004 to 2013, the absolute average deviation of wages, the average wage standard deviation and its coefficient, and the analysis of salary panel data. The degree of integration of the labor market has been analyzed and measured. The results show that: 1 the average wage level in Beijing and Tianjin is in the upstream position in the BeijingTianjin-Hebei region, and the wage levels in Tangshan, Langfang and Qinhuangdao are in the leading position in Hebei Province; the actual wage level in the Beijing-Tianjin-Hebei region is absolutely average from 2004 to 2013. The difference shows a gradual increase, but its growth is gradually slowing down, and the labor market differentiation still exists. 2 The average wage level of the Beijing-Tianjin-Hebei region increases first and then decreases and then approaches the same level. That is, the wage level first diverges and then converges, and the labor market integration develops. 3 The wage levels of 13 cities in the Beijing-Tianjin-Hebei region tended to converge in a decade, but the overall convergence trend was not obvious and slow.

In summary, the process of wage integration in the BeijingTianjin-Hebei region has developed slightly in 2004-2013, but the wage gap between individual cities is still large, and the overall labor market is still in a state of differentiation, accompanied by a slow integration trend.

\section{B. Countermeasures and Suggestions for the Integration of Labor Market in Beijing-Tianjin-Hebei Region}

Based on the above conclusions, this paper proposes the following policies and recommendations for the integration of the labor market in the Beijing-Tianjin-Hebei region:

First, accelerate industrial restructuring and upgrading to create a new capital economic circle.

The primary task of unifying the labor market in the Beijing-Tianjin-Hebei region is to coordinate the development of the industry, and then to optimize the employment structure of the three places. On the whole, the primary industry and the secondary industry in the Beijing-Tianjin-Hebei region have an integration trend, while the degree of integration of the tertiary industry is relatively poor. The phenomenon of labor market segmentation at various industrial levels is more serious, and industrial adjustment and upgrading are imminent. Therefore, for the primary industry, the development of agriculture should continue to be promoted, especially in Hebei. At the same time, on the basis of the existing innovation and upgrading of agriculture, we can use the local tourism resources to develop an agricultural development chain and promote the flow of rural surplus labor. For the secondary industry, all localities should use the location advantage to upgrade the manufacturing industry. The use of high-tech technology to develop the secondary industry, and strive to achieve the interface with the tertiary industry; and for the tertiary industry, Beijing as the capital, the industry should be positioned in high-end, diversified, low-carbon, expand the Zhongguancun Science Park, and vigorously develop Knowledge economy, service economy and green economy under high technology; Tianjin, a port city, should take advantage of the development of strategic tertiary industries such as logistics, aerospace, energy conservation and environmental protection, and biopharmaceuticals to create a leading $R \& D$ base and service industry in the Beijing-Tianjin-Hebei region. District; Hebei should keep up with the pace of Beijing-Tianjin industry 
development, undertake the upgrading and transfer of the capital industry, and build a new industrialization base and an industrial transformation and upgrading experimental zone with advanced manufacturing and emerging industries. The Beijing-Tianjin-Hebei region must form its own industrial clusters with unique characteristics.

Secondly, to build a new capital economic circle, we must constantly improve the layout and form of the Beijing-TianjinHebei urban agglomeration, enhance the functions of small and medium-sized cities in the region, solve the problem of scalelevel faults, and solve Beijing's functions by resolving Beijing's non-capital functions. Problems such as excessive aggregation, opening channels for free flow of factors, reducing the development gap between Beijing, Tianjin and Hebei, and promoting the allocation of quality resources. At the same time, it is necessary to enhance the pivotal function of BeijingTianjin-Hebei in international exchanges, accelerate the integration of international service industry, international service environment and standards, and it is an important platform for Beijing-Tianjin-Hebei to become China's opening up.

Second, reform the regional household registration system and reduce institutional barriers to labor mobility.

The "dualistic" nature of the traditional household registration system is one of the obstacles to labor mobility. Due to the different population size of Beijing-Tianjin-Hebei city, the different welfare attached to each city hukou, and the different levels of welfare enjoyed by the three residents, and Beijing is restricting the continued expansion of the population size, it is impossible to cancel the associations related to the household registration system in the short term. Welfare, the pace of reform of the household registration system in the Beijing-Tianjin-Hebei region is not entirely consistent, but the three regions can innovate and collaborate on the basis of the existing system. At present, the Beijing-Tianjin-Hebei city can gradually separate the household registration system from social welfare, medical insurance, education, and employment security to a certain extent, so that the flow of laborers has no worries, and the sharing of public resources in the three places is promoted. Equity in education and equal medical opportunities. In addition, for household registration management, the "point system" can be adopted, that is, on the basis of extensively soliciting opinions from all walks of life, a transparent, comprehensive, reasonable and dynamic household registration evaluation system is established, which comprehensively considers the basic quality of the population, education, and residence. Time, contribution to the city, and even refinement to participate in public welfare activities. The Beijing-Tianjin-Hebei region should coordinate and cooperate with each other, correct the mechanism for the free movement of labor in the entire region, and achieve the unification of the labor market.

Third, improve the labor employment intermediary market and establish a regional information cooperation mechanism.

China's labor employment intermediary market started late, and its development is slow and not mature. The information asymmetry in the intermediary market will increase the cost of labor mobility. In order to solve this problem, first of all, the governments at all levels in the Beijing-Tianjin-Hebei region should work together to formulate and improve the employment legal system. Relevant departments should impose severe penalties on the acts of fraud in the operation of the intermediary market or similar institutions to safeguard the workers. At the same time, to establish and improve the access and exit mechanism of the employment intermediary market, governments and departments at all levels should strengthen the supervision of the intermediary market and regulate the employment behavior of the Beijing-Tianjin-Hebei labor market. Secondly, the employment intermediary market is divided on the existing basis, and the needs of different regions, different periods, different industries, different groups of people are re-divided into the intermediate market level, and the clear development direction is confirmed to provide personalized services for the diversified objects. Finally, the Beijing-Tianjin-Hebei region should accelerate the development of information technology, establish an information Internet system in the region, and establish a cooperative mechanism of institutionalization, specialization, and informationization. The government should regularly conduct information exchange and dialogue on issues that arise Discuss the future direction of the labor market. More importantly, it establishes a database of labor supply and demand between Beijing, Tianjin and Hebei, establishes archives for each worker, regularly summarizes and analyzes laborer information, and grasps the supply and demand of labor in the Beijing-Tianjin-Hebei region in real-time and dynamically. On this basis, human resources collaboration training in the three places will be carried out to form a unified training plan.

\section{REFERENCES}

[1] Topel R H. Local Labor markets[J]. Journal of Political Economy, 1986, 94(3):111-143.

[2] Barro R J , Xavier Sala-i-Martin. Convergence[J]. Journal of Political Economy, 1992, 100(1):223-251.

[3] Blanchard, O. J., and L. F. Katz. Regional Evolutions[J].Brookings Paper of Economic Activities, 1992, (1):1-61.

[4] Borjas, G. J. Does Immigration Grease the Wheels of the Labor Market? [J].Brookings Papers on Economic Activity, 2001,(1): 69-119.

[5] Du Yang, Cai Fang. The Regional Convergence of Chinese Manufacturing Industries And The Integration of Labor Market[J]. The Journal of World Economy,2004(8):42-49. (In Chinese)

[6] Yang Tao, Sheng Liugang. Wages and Returns to Education in Chinese Cities[J].China Economic Quarterly,2007,6(3):817-840. (In Chinese)

[7] Zhou Shen, Yi Miao. China's Labor Market Integration and Economic Openness[J].Journal of Zhongnan University of Economics and Law,2010(6):11-18. (In Chinese)

[8] Zhao Sanwu, Qian Xueya. The Study on Regional Integration of China's Labor Market in View of Price Index[J].Statistics and Decisions,2014(21):99-101. (In Chinese)

[9] Chen Hongxia, Xi Qiangmin. Study on Measurement and Determinants of Urban Labor Market Integration in Beijing-Tianjin-Hebei Area[J].China Soft Science, 2016(2):81-88. (In Chinese)

[10] Chen Ying. An Analysis on the Integration of China's Labor Market Segmentation: From the Perspective of Wage Convergence[J].Journal of Yunnan University of Finance and Economics,2013(1): 61-69. (In Chinese) 